\title{
Bridging the Divide-Understanding Primary Care and Specialty Care Perspectives on Chronic Disease Co-management: a National Survey
}

J Gen Intern Med 36(7):2164-6

DOI: $10.1007 / \mathrm{s} 11606-020-05877-0$

(c) Society of General Internal Medicine 2020

\section{INTRODUCTION}

Specialists and primary care providers (PCP) generally manage complex chronic diseases in silos, and delineation of responsibilities is often unclear. ${ }^{1-3}$ We aimed to compare the similarities and differences in perception and practice across three complex conditions as it relates to the delineation of responsibilities, perceived roles, and communication. We also aimed to identify factors most strongly associated with a clear delineation of responsibilities, as one aspect of coordinated care.

\section{METHODS}

We conducted an online, cross-sectional 42-question survey of the American College of Physicians members, using the Internal Medicine Insider Research Panel. Eligible PCPs completed training and were active in medicine, and spent $\geq 25 \%$ of their time in direct patient care with a predominant outpatient practice. We used three case scenarios of chronic conditions with high-intensity specialty care needs with varying prevalence in primary care clinics: (1) moderate-to-severe ulcerative colitis (UC) treated with azathioprine, (2) hepatitis C-related cirrhosis and ascites, and (3) insulin-dependent diabetes. Questions focused on four domains: (1) physician roles, (2) comfort level managing disease aspects, (3) provider-provider communication, and (4) access to specialists. The complete survey was tested for face validity using a small group of PCPs.

\section{RESULTS}

The survey was completed by 323 respondents with a $55 \%$ response rate. Nearly three-quarters of PCPs feel that there is a clear delineation of responsibilities between PCPs and specialists as it relates to the care of patients with ulcerative colitis, cirrhosis, and insulin-dependent

This study has not been presented previously.

Received April 7, 2020

Accepted April 28, 2020

Published online June 4, 2020 diabetes. Perceived levels of responsibility vary by specific role and disease state and are reported in Table 1. A majority of PCPs perceived that care coordination within their practices was very $(23.5 \%)$ or somewhat $(55.4 \%)$ effective, though less felt, very $(13.6 \%)$ or somewhat $(47.4 \%)$ satisfied with the quality of communication and the quality of co-management $(22.6 \%$ and $48.0 \%$, respectively) with specialists. Telephone calls and messaging through the electronic medical record were the most common modalities of communication for providers who comanage patients with chronic disease.

In addition, a minority of PCPs felt that specialists were very easy or somewhat easy to access; these numbers are generally similar across disease states. Perceived effectiveness of care coordination was strongly associated with clear delineation of responsibilities across disease states (Table 2). An association between a clear delineation of responsibilities and satisfaction in the quality of communication with specialists was also evident in UC care and with the quality of comanagement with specialists for both UC and cirrhosis care (Table 2).

\section{DISCUSSION}

Coordinated chronic disease care requires a clear delineation in the role between providers for the effective transfer of accurate timely clinical information, effective communication, and shared decision-making. While many perceive that a clear delineation in role exists between primary care and specialty care as it related to the treatment of complex chronic disease, this study demonstrates that we continue to see a substantial number of PCPs who do not perceive that a delineation exists. A perceived clear delineation of responsibilities seems to be a marker of effective care coordination with specialists, and satisfaction with the quality of both communication and comanagement with specialists. While a majority of providers perceive that communication is effective, a general lack of satisfaction with communication and co-management suggests there is room for improvement.

Patients with complex conditions often require comanagement, the shared management for the disease where both practices are concurrently active in the patient's care, and the specialty practice provides temporary guidance and ongoing follow-up of the patient for one specific condition. While comanagement improves outcomes in patients with chronic disease, the best methods of co-managing patients have not been 
Table 1 PCP Perceptions on Roles, Comfort Level, and Access to Specialists Across Disease States

\begin{tabular}{|c|c|c|c|}
\hline & Ulcerative colitis & Cirrhosis & Insulin-dependent diabetes \\
\hline \multicolumn{4}{|c|}{ Delineation of responsibilities } \\
\hline \multicolumn{4}{|c|}{ Is there a clear delineation of responsibilities between you and specialist? } \\
\hline Yes & $234(72.5 \%)$ & $230(71.2 \%)$ & $228(70.6 \%)$ \\
\hline No & $62(19.2 \%)$ & $52(16.1 \%)$ & $66(20.4 \%)$ \\
\hline Not sure & $27(8.3 \%)$ & $41(12.7 \%)$ & $29(9.0 \%)$ \\
\hline \multicolumn{4}{|c|}{ Who is responsible for the primary management of decompensation, poor disease control? } \\
\hline Primary care & $34(10.5 \%)$ & $45(13.9 \%)$ & $40(12.4 \%)$ \\
\hline Specialist & $277(85.8 \%)$ & $256(79.3 \%)$ & $268(83.0 \%)$ \\
\hline Not sure & $12(3.7 \%)$ & $22(6.8 \%)$ & $15(4.6 \%)$ \\
\hline \multicolumn{4}{|c|}{ Who is responsible for the primary management of immunizations? } \\
\hline Primary care & $312(96.6 \%)$ & & \\
\hline Specialist & $4(1.2 \%)$ & & \\
\hline Not sure & $7(2.2 \%)$ & & \\
\hline \multicolumn{4}{|c|}{ Who is responsible for the primary management of cancer screening? } \\
\hline Primary care & $287(88.9 \%)$ & $70(21.7 \%)$ & \\
\hline Specialist & $24(7.4 \%)$ & $228(70.6 \%)$ & \\
\hline Not sure & $12(3.7 \%)$ & $25(7.7 \%)$ & \\
\hline \multicolumn{4}{|c|}{ Who is responsible for the primary management of osteoporosis/foot exam screening? } \\
\hline Primary care & $313(96.6 \%)$ & & $229(70.9 \%)$ \\
\hline Specialist & $1(0.3 \%)$ & & $64(19.8 \%)$ \\
\hline Not sure & $9(2.8 \%)$ & & $30(9.3 \%)$ \\
\hline \multicolumn{4}{|c|}{ Comfort level } \\
\hline \multicolumn{4}{|c|}{ How comfortable are you with acting as the primary contact of care? } \\
\hline Very comfortable & $227(70.3 \%)$ & $164(50.8 \%)$ & $231(71.5 \%)$ \\
\hline Somewhat comfortable & $83(25.7 \%)$ & $120(37.2 \%)$ & $68(21.0 \%)$ \\
\hline Neutral & $7(2.2 \%)$ & $25(7.7 \%)$ & $16(5.0 \%)$ \\
\hline Somewhat uncomfortable & $3(0.9 \%)$ & $11(3.4 \%)$ & $8(2.5 \%)$ \\
\hline Very uncomfortable & $3(0.9 \%)$ & $3(0.9 \%)$ & $0(0.0 \%)$ \\
\hline \multicolumn{4}{|l|}{ Ease of access to specialist } \\
\hline Very easy & $44(13.6 \%)$ & $31(9.6 \%)$ & $29(9.0 \%)$ \\
\hline Somewhat easy & $122(37.8 \%)$ & $101(31.3 \%)$ & $113(35.0 \%)$ \\
\hline Neutral & $55(17.0 \%)$ & $67(20.7 \%)$ & $58(18.0 \%)$ \\
\hline Somewhat difficult & $81(25.1 \%)$ & $92(28.5 \%)$ & $98(30.3 \%)$ \\
\hline Very difficult & $21(6.5 \%)$ & $32(9.9 \%)$ & $25(7.7 \%)$ \\
\hline
\end{tabular}

determined. $^{4,5}$ This study's strengths include a nationally representative sample with a relatively high response rate, suggesting generalizability of these results. However, use of case examples may limit generalizability to other disease states, and survey responses are limited to the PCP perspective.
Effective coordination results from shared goals, shared insight, and mutual respect. ${ }^{6}$ This requires individual knowledge of interconnected roles. In this context, understanding PCPs' perceptions as to delineation of roles in co-managing patients is a first step towards understanding barriers to coordination in efforts to improve chronic disease care. This is

Table 2 Association Between Communication/Co-management and a Clear Delineation of Responsibilities Between Primary Care and Specialist

\begin{tabular}{|c|c|c|c|c|c|c|}
\hline & \multicolumn{2}{|c|}{ Ulcerative colitis scenario } & \multicolumn{2}{|c|}{ Cirrhosis scenario } & \multicolumn{2}{|c|}{ Diabetes scenario } \\
\hline & $\begin{array}{l}\text { Odds } \\
\text { ratio }\end{array}$ & $\begin{array}{l}95 \% \text { confidence } \\
\text { interval }\end{array}$ & $\begin{array}{l}\text { Odds } \\
\text { ratio }\end{array}$ & $\begin{array}{l}95 \% \text { confidence } \\
\text { interval }\end{array}$ & $\begin{array}{l}\text { Odds } \\
\text { ratio }\end{array}$ & $\begin{array}{l}95 \% \text { confidence } \\
\text { interval }\end{array}$ \\
\hline \multicolumn{7}{|c|}{ Communication effectiveness } \\
\hline Very effectively & 3.20 & $1.27,8.03$ & 3.81 & $1.54,9.42$ & 3.25 & $1.34,7.91$ \\
\hline Somewhat effectively & 1.92 & $0.87,4.21$ & 2.71 & $1.24,5.92$ & 2.17 & $1.00,4.71$ \\
\hline Neutral & 1.22 & $0.45,3.29$ & 0.99 & $0.38,2.62$ & 2.71 & $0.96,7.64$ \\
\hline $\begin{array}{l}\text { Somewhat } \\
\text { ineffectively }\end{array}$ & Omitted & Omitted & Omitted & Omitted & Omitted & Omitted \\
\hline Very ineffectively & Ref & Ref & Ref & Ref & Ref & Ref \\
\hline \multicolumn{7}{|c|}{ Communication satisfaction } \\
\hline Very satisfied & 4.11 & $1.15,14.76$ & 2.70 & $0.76,9.63$ & 2.05 & $0.55,7.56$ \\
\hline Somewhat satisfied & 2.94 & $1.02,8.52$ & 1.75 & $0.60,5.15$ & 1.20 & $0.39,3.67$ \\
\hline Neutral & 1.30 & $0.41,4.09$ & 1.20 & $0.37,3.90$ & 0.91 & $0.27,3.07$ \\
\hline Somewhat dissatisfied & 1.20 & $0.39,3.66$ & 0.99 & $0.32,3.10$ & 0.75 & $0.23,2.44$ \\
\hline Very dissatisfied & Ref & Ref & Ref & Ref & Ref & Ref \\
\hline \multicolumn{7}{|c|}{ Co-management satisfaction } \\
\hline Very satisfied & 12.60 & $2.03,78.28$ & 7.73 & $1.29,46.44$ & 2.11 & $0.35,12.71$ \\
\hline Somewhat satisfied & 6.86 & $1.20,39.12$ & 6.16 & $1.08,35.05$ & 1.22 & $0.22,6.93$ \\
\hline Neutral & 2.48 & $0.41,14.90$ & 3.88 & $0.64,23.54$ & 0.81 & $0.13,4.87$ \\
\hline Somewhat dissatisfied & 2.42 & $0.40,14.73$ & 2.20 & $0.36,13.37$ & 0.81 & $0.13,4.97$ \\
\hline Very dissatisfied & Ref & Ref & Ref & Ref & Ref & Ref \\
\hline
\end{tabular}

Omitted due to collinearity 
important to PCPs as a group and to specialists who comanage these patients as we work towards improving care coordination for these complex patients.

Shirley Cohen-Mekelburg, M.D., M.S. ${ }^{1,2,3}$

Jacob Kurlander, M.D., M.S. ${ }^{1,2,3}$

Emma Steppe, M.S. ${ }^{3}$

Sameer Saini, M.D., M.S. ${ }^{1,2,3}$

${ }^{1}$ Division of Gastroenterology and Hepatology,

University of Michigan,

3912 Taubman Center, 1500 E. Medical Center

Drive, SPC 5362, Ann Arbor, MI 48109, USA

${ }^{2}$ Center for Clinical Management Research, Veterans

Affairs Ann Arbor Health System,

Ann Arbor, MI, USA

${ }^{3}$ Institute for Healthcare Policy and Innovation,

Ann Arbor, MI, USA

Corresponding Author: Shirley Cohen-Mekelburg, M.D., M.S.; Division of Gastroenterology and Hepatology, University of Michigan 3912 Taubman Center, 1500 E. Medical Center Drive, SPC 5362, Ann Arbor, MI 48109, USA (e-mail: shcohen@umich.edu).

Funding Information This study was funded in part by a University of Michigan MPRoVE Research Challenge Grant.

\section{Compliance with Ethical Standards:}

Conflict of Interest: The authors declare that they do not have a conflict of interest.

\section{REFERENCES}

1. Committee on Quality of Health Care in America, \& Institute of Medicine Staff. Crossing the quality chasm: a new health system for the 21st century. Washington (DC): National Academies Press; 2001.

2. Enthoven AC. Integrated delivery systems: the cure for fragmentation. Am J Manag Care 2009; 15:S284-90.

3. Sinaiko AD, Landrum MB, Meyers DJ, et al. Synthesis Of Research On Patient-Centered Medical Homes Brings Systematic Differences Into Relief. Health Aff (Millwood) 2017;36:500-8.

4. Larochelle JL, Feldman DE, Levesque JF. The primary-specialty care interface in chronic diseases: patient and practice characteristics associated with co-management. Healthc Policy 2014;10:52-63.

5. Ayanian JZ, Landrum MB, Guadagnoli E, Gaccione P. Specialty of ambulatory care physicians and mortality among elderly patients after myocardial infarction. N Engl J Med 2002;347:1678-86.

6. Gittell JH, Godfrey $\mathbf{M}$, Thistlethwaite J. Interprofessional collaborative practice and relational coordination: improving healthcare through relationships. J Interprof Care 2013;27:210-3.

Publisher's Note: Springer Nature remains neutral with regard to jurisdictional claims in published maps and institutional affiliations. 